\title{
L'enceinte des premier et second âges du Fer de la Fosse Touzé (Courcelles-sur-Mer, Calvados)
}

Patrice Brun

\section{(2) OpenEdition}

\section{Journals}

Édition électronique

URL : http://journals.openedition.org/rao/2230

DOI : 10.4000/rao.2230

ISBN : 978-2-7535-3432-2

ISSN : $1775-3732$

\section{Éditeur}

Presses universitaires de Rennes

\section{Édition imprimée}

Date de publication : 25 décembre 2013

Pagination : $316-317$

ISBN : 978-2-7535-3430-8

ISSN : 0767-709X

\section{Référence électronique}

Patrice Brun, «L'enceinte des premier et second âges du Fer de la Fosse Touzé (Courcelles-sur-Mer, Calvados) », Revue archéologique de l'Ouest [En ligne], 30 | 2013, mis en ligne le 25 décembre 2013, consulté le 05 décembre 2020. URL : http://journals.openedition.org/rao/2230 ; DOI : https://doi.org/ $10.4000 /$ rao. 2230

\section{Ce document a été généré automatiquement le 5 décembre 2020.}

Tous droits réservés 


\title{
L'enceinte des premier et second âges du Fer de la Fosse Touzé (Courcelles-sur-Mer, Calvados)
}

\author{
Patrice Brun
}

\section{RÉFÉRENCE}

Jahier I., 2011 - L'enceinte des premier et second âges du Fer de la Fosse Touzé (Courcelles-surMer, Calvados). Entre résidence aristocratique et place de collecte monumentale, Documents d'archéologie française, $\mathrm{n}^{\circ} 104$, Paris, éditions de la Maison des sciences de l'homme. (ISBN 978-2-7351-1122-0, $44 €$ )

1 Cet ouvrage, réalisé sous la direction d'Ivan Jahier est une belle réussite éditoriale. Il est le $104^{\mathrm{e}}$ numéro des Documents d'archéologie française qui se caractérisent par leur qualité formelle. Riche de 246 pages, 95 figures et d'annexes présentant le catalogue des céramiques et les plans généraux du site, il correspond au type de monographies dont notre discipline a le plus grand besoin.

2 Le site en question a fait l'objet, en 1997, d'une fouille préventive sur la commune, côtière de la Manche, de Courseulles-sur-Mer située dans le périmètre de l'agglomération de communes du Grand Caen. Un enclos fossoyé carré d'un hectare de superficie y avait été repéré en prospection aérienne. L'intervention de terrain, durant laquelle cette enceinte et l'espace interne ont été fouillés dans leur totalité, a montré qu'elle fut l'occupation principale de la zone.

3 Les vestiges de cet établissement recelaient 10500 tessons de poterie. Les comparaisons typologiques, en particulier avec les types de la culture de l'Aisne-Marne, permettent de dater cette occupation du $v^{e}$ et du début du $\mathrm{IV}^{\mathrm{e}} \mathrm{s}$. av. J.-C. Figuraient aussi des indices d'une production d'objets en cuivre et d'activités de meunerie, saunerie, filage, tissage et 2200 restes de faune. Les modifications mises en évidence ont permis de distinguer quatre phases. De nombreux bâtiments ont été identifiés, surtout à l'intérieur. Il s'agit 
pour la plupart de probables greniers sur pilotis à quatre poteaux, répartis en deux groupes d'une douzaine. Quelques bâtiments plus vastes complétaient l'ensemble: de plan quadrangulaire ou à abside dans deux cas datés de la phase ancienne et de plan circulaire pour deux autres plus récents, dont le plus grand. Six sépultures contemporaines de cette enceinte se trouvaient dans sa proximité immédiate. Quelques ossements humains ont également été découverts, dispersés dans les structures d'habitat.

Les structures et le mobilier archéologiques sont soigneusement décrits et illustrés, les interprétations prudemment argumentées, en précisant bien les limites des hypothèses formulées. Il s'agit en somme d'un précieux outil de travail, d'autant plus que l'établissement correspond à un type encore peu connu en France et qui s'inscrit probablement entre la ferme ou le hameau ordinaire et l'agglomération fortifiée. En dépit de l'absence d'objets marquant l'éventuelle appartenance des occupants à l'élite sociale, hormis la richesse relative de l'une des tombes, la monumentalité, d'ailleurs croissante, de l'enceinte et l'organisation interne des bâtiments incitent à l'inscrire sur le même plan que les Herrenhöfe de nos collègues allemands et les ringforts de nos collègues britanniques, c'est-à-dire des domaines aristocratiques. L'hypothèse d'une place de collecte monumentale, proposée, elle aussi, dans le sous-titre de l'ouvrage, est moins convaincante. Le nombre de greniers s'avère certes assez élevé : une trentaine, mais ramené à une durée d'un siècle d'occupation, il ne correspond qu'à sept ou huit structures de stockage par génération de vingt-cinq ans; ce qui ne représente au maximum que trois ou quatre fois la capacité de stockage aérien de la moyenne des fermes ouvertes répertoriées du Bronze final au milieu du second âge du Fer. En d'autres termes, si cette capacité exprime une aisance indiscutable, elle peut difficilement être interprétée comme une réserve à caractère politique, issue du prélèvement de taxes et destinée à supporter des besoins militaires ou des stratégies de redistribution.

5 L'ouvrage possède aussi le mérite de replacer ce type d'établissements dans un large contexte chronologique et spatial en interrogeant, notamment, leur séquence d'apparition et de disparition dans le nord-ouest français. Bien que la documentation disponible soit encore insuffisante pour généraliser, il apparaît d'ores et déjà clair que nous devrions pouvoir mieux comprendre, prochainement, nombre de points clés sur l'évolution des modalités d'occupation du paysage et, par conséquent, de l'organisation politique et de la structure foncière des sociétés protohistoriques. Ce livre doit, en tout cas, figurer dans toute bibliothèque d'archéologie, voire de chercheur intéressé par la protohistoire de la France.

\section{AUTEURS}

\section{PATRICE BRUN}

Université Paris 1 Panthéon-Sorbonne 